\title{
Kronik böbrek yetmezliği ile başvuran Bardet Biedl sendromlu bir olgu
}

\author{
A patient with Bardet-Biedl syndrome presenting with chronic renal failure
}

Serhan Pişkinpaşa*, Hadim Akoğlu, Ezgi Çoşkun Yenigün, Eyüp Koç, Didem Turgut, İpek Işık Gönül, Fatih Dede

Nefroloji kliniği (Dr. S. Pişkinpaşa, Dr. H. Akoğlu, Dr. E. Ç. Yenigün, Dr. E. Koç, Dr. D. Turgut, Doç. Dr. F. Dede), Ankara Numune Eğitim ve Araştırma Hastanesi TR-06100 Ankara, Patoloji Anabilim Dalı (Doç. Dr. İ. I. Gönül), Gazi Üniversitesi Tıp Fakültesi TR-06500 Ankara

\section{Özet}

Bardet-Biedl Sendromu obezite, retinal distrofi, dismorfik ekstremiteler, mental retardasyon, endokrinolojik ve renal anormallikler ile karakterize, otozomal resesif geçişli nadir görülen bir hastalıktır. Renal tutulum hastalığın major tanı kriterlerinden olup; kronik böbrek hastalığı bu sendromda görülen en sık ölüm nedenidir. Bu nedenle, renal hasarın erken teşhisi prognostik öneme sahiptir. Bu yazıda, nadir gözlenen Bardet-Biedl sendromuna eşlik eden kronik böbrek hastalığı ve konuyla ilgili literatür gözden geçirildi.

Anahtar sözcükler: Bardet-Biedl sendromu, obezite, mental retardasyon, hipertansiyon, kronik böbrek hastalı̆̆1

\begin{abstract}
Bardet-Biedl syndrome is a rare autosomal recessive disease characterized by obesity, retinal dystrophy, dysmorphic extremities, mental retardation, endocrine and renal abnormalities. Renal involvement is recognized as a cardinal feature. Chronic kidney disease is major cause of mortality in Bardet-Biedl syndrome. In this report, we discussed a patient presenting with chronic kidney disease and Bardet-Biedl syndrome due to its rarity in the aspect of the literature.
\end{abstract}

Keywords: Bardet-Biedl syndrome, obesity, mental retardation, hypertension, chronic kidney disease

Geliş tarihi/Received: 07 Ekim 2011; Kabul tarihi/Accepted: 22 Kasım 2012

\section{*İletişim adresi:}

Dr. Serhan Pişkinpaşa, Nefroloji Kliniğgi, Ankara Numune Eğitim ve Araştırma Hastanesi, TR06100 Ankara. E-posta: svppasa@yahoo.com

\section{Giriş}

Bardet-Biedl sendromu, otozomal resesif geçişli nadir bir hastalıktır [1]. Hastalık tanısında retinal distrofi, polidaktili, obezite, öğrenme güçlükleri ve erkekte hipogonadizm/kadında menstrüel düzensizliklere ek olarak; anatomik ve fonksiyonel renal anormallikler günümüzde major tanı kriteri olarak kabul edilmektedir [2]. Böbrek tutulumu; asemptomatik anatomik varyasyonlardan, son dönem böbrek hastalığına uzanan geniş bir yelpazeyi kapsamaktadır. Hipertansiyon minör ya da major tanı kriteri olmamakla birlikte, hastalığa sık olarak eşlik etmektedir. Kronik böbrek hastalığı, sendromun seyrindeki en sik ölüm nedeni olması nedeniyle prognostik önem göstermektedir [1-8]. 


\section{Olgu sunumu}

Yirmi iki yaşında kadın hasta gebeliği sırasında tespit edilen hipertansiyon ve böbrek fonksiyon testlerinde bozukluk nedeniyle gebelik sonlandırılması sonrasında kliniğimize başvurdu. Hastanın öyküsünde ilkokul mezunu olduğu, okul başarısının yetersiz olduğu, halsizlik, yorgunluk ve adet düzensizliği şikâyetlerinin olduğu, sindaktili nedeniyle bir defa operasyon geçirdiği ve kan basıncı yüksekliği nedeniyle amlodipin ve losartan kullandığı öğrenildi. Poliüri, polidipsi, enüresis, koordinasyon bozukluğu ve davranış problemleri öyküsü bulunmayan hastanın fizik muayenesinde; kan basınc1 150/100 $\mathrm{mmHg}$, obezite (vücut kitle indeksi $34,3 \mathrm{~kg} / \mathrm{m}^{2}$ ), apatik yüz görünümü, soluk konjuktivalar, kısa boyun, sindaktili ve polidaktili tespit edildi. Diğer sistem muayeneleri normaldi. Laboratuvar tetkiklerinde; serum üre: $127 \mathrm{mg} / \mathrm{dL}$, kreatinin: $3,1 \mathrm{mg} / \mathrm{dL}$, glukoz: 94mg/dL, Na: 136mmol/L, K: 4,4mmol/L, Ca: 8,4mg/dL, P: 5,4mg/dL, total protein: 64 g/L, albümin: $37 \mathrm{~g} / \mathrm{L}$, hemoglobin: $9,5 \mathrm{~g} / \mathrm{dL}$, beyaz küre: $6000 / \mathrm{mm}^{3}$, trombosit: 220 $000 / \mathrm{mm}^{3}$ saptand1. Tam otomatik idrar tetkikinde dansite: 1010, protein negatif, mikroskopide beyaz küre: 1/HPF (high power field), kırmızı küre: 1/HPF; spot idrar protein/kreatinin: $0,3 \mathrm{mg} / \mathrm{mg}$ olarak tespit edildi. Apatik yüz görünümü nedeniyle bakılan TSH: 61 (N: 0,34-5,6)uIU/mL, sT4: 0,2 (N: 0,61-1,48)ng/dL, sT3: 2,71 (N: 2,53,9)pg/mL, anti-TPO: 247 (N: 0-9)IU/mL saptanması üzerine hipotiroidizm tanısıyla Ltiroksin $(0,1 \mathrm{mg} /$ gün $)$ tedavisi başland. Tiroid ultrasonografisinde, normal boyutta tiriod bezi, parankim ekosu azalmış, belirgin heterojenite; tiroidit ile uyumlu olarak bulundu. Hastanın menstruel siklusun dördüncü günü bakılan $\mathrm{FSH}: 6,1 \mathrm{mIU} / \mathrm{mL}(\mathrm{N}: 2,9-12)$, LH:2,7mIU/mL (N:1,5-8), estradiol 58pg/mL (N:1-147), progesteron: 6,5 ng/mL (N:0,21,4), DHEA-S: 53,8ug/dL (N:38-388) tespit edildi. Göz muayenesinde stabismus, katarakt, astigmatizm ve renk körlüğü olmadığ1 saptand1, retinal distrofi varlı̆g 1 tespit edildi. Psikiyatrik değerlendirmede orta derecede mental retardasyon tespit edildi. Yapılan renal ultrasonografisinde her iki böbrek normal boyutlarda, lobüle, parankim ekojenitesinde grade 2 artış saptandı. Böbrek sintigrafisinde (DTPA), ileri derecede azalmış kanlanma ve ekstraksiyon fonksiyonlarında yetersizlik izlendi. Belirgin ekskresyon saptanmadı. Yapılan böbrek biyopsisi, glomerüllerin üçte ikisinde global glomeruloskleroz, bazı glomerüllerde mezengiosellüler alanlar, interstisyumda trikrom boyası ile kollojenize bağ doku artışı, bazı tübül sitoplazmalarında vakuolizasyon, hafif derecede dilatasyon ve tübüler atrofi şeklinde raporlandı (Resim 1). Hastanın elektrokardiyografi ve ekokardiyografi tetkiklerinde patolojiye rastlanmadi. Hipotirodizm nedeniyle medikal tedavi ihtiyacı devam eden hastaya, mevcut bulgularla Bardet-Biedl sendromu ve eşlik eden kronik böbrek hastalığı tanısı konularak medikal tedavisi düzenlendi ve ayaktan takibe alındı.

\section{Tartışma}

Bardet-Biedl sendromu nadir görülen, heterojen genetik özelliklere sahip bir hastalıktır. Tanımlanmış 15 farklı gen mutasyonundan herhangi birisiyle ortaya çıkabilmektedir [1-4] Hastalığın tanısında 4 major ya da 3 major +2 minör kriterin bulunması gerekmektedir (Tablo 1) $[1,3,5]$. Hastalığın heterojen genetik özelliklere sahip olması ve oligogenik kalıtım özellikliği genotip-fenotip korelasyonunu güçleştirmektedir [3, 4].

Ekstremite anomalileri en erken görülen belirtileri oluşturmaktadır. Obezite, göz anomalileri ve öğrenme güçlüğü sıklıkla çocukluk yaşlarında ortaya çıkmaktadır $[1,2]$. Hastalığın seyrinde diabetes mellitus, hipertansiyon, gonadal disfonksiyon ve kardiyak anomaliler görülebilmektedir $[1,2,6,7]$.

Gonadal disfonksiyon erkek hastalarda kadınlara göre çok daha fazla görülmektedir. Hipogonadizm sıklıkla hipogonadotropik özellikte olup, erkek hastalarda doğumda küçük penis boyutu ve azalmış testis volümü eşlik edebilmektedir. Erkek hastaların tamamında hipogonadizm bildirilmektedir [1, 3, 8]. Kadın hastalarda sıklıkla menstruel siklus döneminin gecikmesi ve menstruel düzensizlik görülmektedir, ancak literatürde birçok sağlıklı gebelik ve doğum gerçekleştiği bildirilen kadın hastalar bulunmaktadır [9]. Kadın 
hastalarda ayrıca $\% 25$ 'e varan oranlarda genital malformasyon görülebilmektedir [8]. Fallop tüpleri, uterus ve overlerde hipoplazi, vajinal atrezi, hematokolpos ve vezikovajinal fistül bildirilen anomaliler arasındadır $[8,9]$.

Bardet-Beidl sendromunda \%100'e varan s1kl1kta anatomik veya fonksiyonel renal tutulum görülmektedir [2,7]. Asemptomatik anatomik varyasyonlar (medüller kistler, kaliks anomalileri), fetal lobulasyon, böbrek boyutlarında küçülme, kontürlerde irregülarite, renal arteriol oklüzyonları ve mikroanevrizmalar şeklinde anatomik bozukluluklar yanında; idrar konsantrasyon defekti, mezengial proliferasyon ve spesifik olmayan glomeruler/tübülointerstisyel lezyonlar şeklinde fonksiyonel bozukluklar da gözlenebilmektedir [10-13]. Bardet-Biedl sendromunda hipertansiyon sıklığı \%50-66 arasında bildirilmektedir. Hipertansiyonun nedeni net olarak ortaya konamamış olmakla birlikte; direkt olarak mutant genin etkisi, vasküler anomaliler, renal parankimal hastalık ya da obeziteyle ilişkili olabileceği öne sürülmektedir $[2,10]$. O'Dea ve arkadaşlarının yaptığ 1 çalışmada, Bardet-Biedl sendromlu hastaların \%25'inde kronik böbrek hastalığ tespit edilirken, mortalite görülen olgularda bu oranın \%75'e çıktı̆̆ bildirilmiştir [2]. Son dönem böbrek yetmezliği bu sendromun majör mobidite ve mortalite nedeni olarak rapor edilmektedir [1, 2, 12-16]. Yakın zamanda son dönem böbrek yetmezliği nedeniyle renal transplantasyon yapılan hastalarda olumlu sonuçlar bildirilmektedir [17-18]. Bizim hastamızda hipertansiyon ve kronik böbrek hastalığı dışında anatomik ve fonksiyonel bozukluk tespit edilmedi. Hastamızın renal ultrasonografisinde Bardet-Biedl sendromlu hastalarda görülebilen böbrek boyutlarında küçülme, kontürlerde irregülarite, medüller kistler ve kaliks anomalileri saptanmadı. Yapılan böbrek biyopsisinde literatürde daha önce de tanımlanmış, spesifik olmayan glomerüler ve tübüler lezyonlar tespit edildi. $\mathrm{Bu}$ patolojik bulguların çoğunun kronik böbrek hastalığı olan hastalarda da görülebildiği dikkate alındığında hastalığa spesifik olmadığı söylenebilir.

Bardet-Biedl sendromu her ne kadar nadir olarak görülse de, farklı klinik görünümleri ve sık böbrek tutulumu göstermesi nedeniyle önem kazanmaktadır. Böbrek tutulumunun en sık mortalite nedeni olduğu göz önüne alındığında; ayrıntılı değerlendirme ile tanı/tedavi planının erken dönemde sağlanması, yaşam kalitesi ve hasta sağ kalımı açısından önemli olup; gerekli replasman tedavilerinin planlanması açısından da yol gösterici olacaktır.

Tablo 1. Bardet-Biedl sendromu tanı kriterleri.

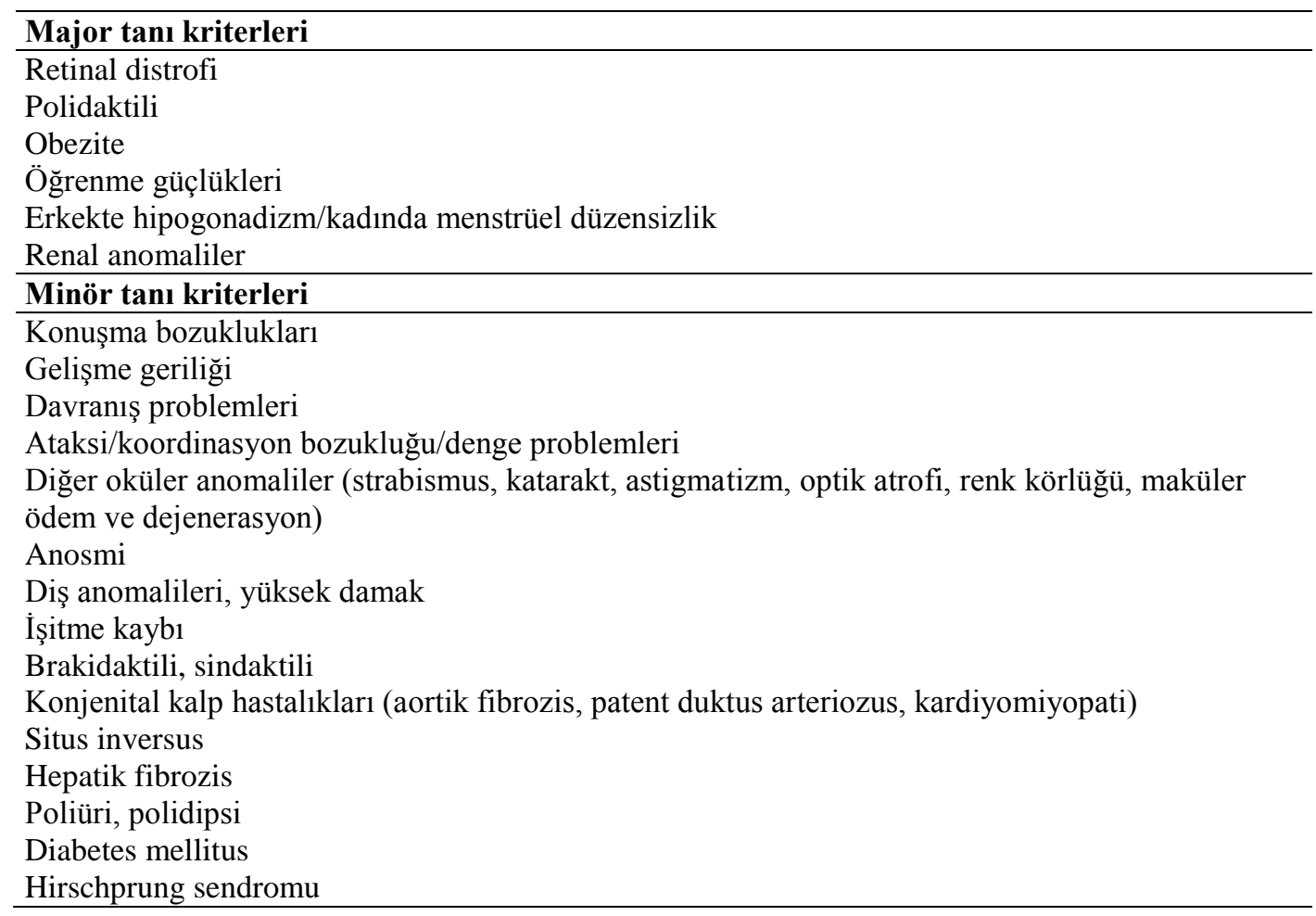




\section{Kaynaklar}

1. Beales PL, Elcioglu N, Woolf AS, Parker D, Flinter FA. New criteria for improved diagnosis of Bardet-Biedl syndrome: Results of a population survey. J Med Genet 1999; 36: 437-46.

2. O'Dea D, Parfrey PS, Harnett JD, Hefferton D, Cramer BC, Green J. The importance of renal impairment in the natural history of Bardet-Biedl syndrome. Am J Kidney Dis 1996; 27: 776-83.

3. Putoux A, Attie-Bitach T, Martinovic J, Gubler MC. Phenotypic variability of Bardet-Biedl syndrome: focusing on the kidney. Pediatr Nephrol 2012; 27: 7-15.

4. Deveault C, Billingsley G, Duncan JL, Bin J, Theal R, Vincent A, Fieggen KJ, Gerth C, Noordeh N, Traboulsi EI, Fishman GA, Chitayat D, Knueppel T, Millán JM, Munier FL, Kennedy D, Jacobson SG, Innes AM, Mitchell GA, Boycott K, Héon E.BBS genotype-phenotype assessment of a multiethnic patient cohort calls for a revision of the disease definition. Hum Mutat 2011; 32: 610-9.

5. Tobin JL, Beales PL. Bardet-Biedl syndrome: beyond the cilium. Pediatr Nephrol 2007; 22: 926-36.

6. Harnett JD, Green JS, Cramer BC, Johnson G, Chafe L, McManamon P, Farid NR, Pryse-Phillips W, Parfrey PS. The spectrum of renal disease in LaurenceMoon-Biedl syndrome. N Engl J Med 1988; 319: 615-8.

7. Elbedour K, Zucker N, Zalzstein E, Barki Y, Carmi R. Cardiac abnormalities in the Bardet-Biedl syndrome: echocardiographic studies of 22 patients. Am J Med Genet 1994; 15; 52: 164-9.

8. Moore SJ, Green JS, Fan Y, Bhogal AK, Dicks E, Fernandez BA, Stefanelli M, Murphy C, Cramer BC, Dean JC, Beales PL, Katsanis N, Bassett AS, Davidson WS, Parfrey PS. Clinical and genetic epidemiology of Bardet-Biedl syndrome in Newfoundland: a 22-year prospective, population-based, cohort study. Am J Med Genet A 2005; 132: 352-60.

9. Green JS, Parfrey PS, Harnett JD, Farid NR, Cramer BC, Johnson G, Heath O, McManamon PJ, O'Leary E, Pryse-Phillips W. The cardinal manifestations of Bardet-Biedl syndrome, a form of Laurence-Moon-Biedl syndrome. N Engl J Med 1989; 321: 1002-9.

10. Baskın E, Balkancı F, Cekirge S, Şener C, Saatçi U. Renal vascular abnormalities in Bardet-Biedl syndrome. Pediatr Nephrol 1999; 13: 787-9.

11. Gourdol O, David L, Colon S, Bouvier R, Ayral A, Aguercif M, François R. Renal involvement in the Laurence-Moon-Bardet-Biedl syndrome. Apropos of 3 cases. Pediatrie 1984; 39: 175-81.

12. Hurley RM, Dery P, Norady MB, Drummond KN. The renal lesion of the Laurence-Moon-Biedl syndrome. J Pediatr 1975; 87: 206-9.

13. Churchill DN, McManamon P, Hurley RM. Renal disease-a sixth cardinal feature of the Laurence-Moon-Biedl syndrome. Clin Nephrol 1981; 16: 151-4.

14. Uçar B, Yakut A, Kural N, Büyükaşık F, Vardareli E. Renal involvement in the Laurence-Moon-Bardet-Biedl syndrome: report of five cases. Pediatr Nephrol 1997; 11: 31-5.

15. Balal M, Paydaş S, Karayaylalı İ, Seyrek N. İnsülin Bağımlı Diabetes Mellitus'lu ve Böbrek Yetersizliği Olan LMB Sendromu. Türk Nefroloji ve Transplantasyon Dergisi 2004; 13: 177-9.

16. Köksal Ş, Dede F, Yenigün E, Pişkinpaşa S, Akoğlu H, Öztürk R, Koç E, Odabaş AR. Kronik Böbrek Yetmezliğinin Nadir Bir Sebebi: Bardet Biedl Sendromu. Klinik Seriler, Nefroloji, Diyaliz ve Hipertansiyon 2009; 3: 5-7.

17. Sharifian M, Dadkhah-Chimeh M, Einollahi B, Nafar M, Simforoush N, Basiri A, Otukesh H. Renal transplantation in patients with Bardet-Biedl syndrome. Arch Iran Med 2007; 10: 339-42.

18. Langer RM, Földes K, Szalay L, Járay J. Laurence-Moon-Bardet-Biedl syndrome for kidney transplantation at the age of 57 years. Transplant Proc 2005; 37: 42234. 